https://helda.helsinki.fi

Characteristics associated with initiation of hormone replacement therapy among Finnish women : A register-linkage study

Jalava-Broman, J.

2016-07

Jalava-Broman , J , Makinen , J , Sillanmaki , L , Vahtera , J \& Rautava , P 2016 , '

Characteristics associated with initiation of hormone replacement therapy among Finnish

women : A register-linkage study ' , Maturitas , vol. 89 , pp. 73-78 . https://doi.org/10.1016/j.maturitas.2016.04.011

http://hdl.handle.net/10138/224043

https://doi.org/10.1016/j.maturitas.2016.04.011

publishedVersion

Downloaded from Helda, University of Helsinki institutional repository.

This is an electronic reprint of the original article.

This reprint may differ from the original in pagination and typographic detail.

Please cite the original version. 


\title{
Characteristics associated with initiation of hormone replacement therapy among Finnish women: A register-linkage study
}

\author{
J. Jalava-Broman ${ }^{\mathrm{a}, *}$, J. Mäkinen ${ }^{\mathrm{b}}$, L. Sillanmäki ${ }^{\mathrm{c}}$, J. Vahtera ${ }^{\mathrm{a}}$, P. Rautava ${ }^{\mathrm{a}, \mathrm{d}}$ \\ a Department of Public Health, University of Turku, Turku, Finland \\ ${ }^{\mathrm{b}}$ Department of Obstetrics and Gynecology, Turku University Hospital, Turku, Finland \\ c Department of Public Health, Clinicum, Faculty of Medicine, University of Helsinki, Finland \\ d Clinical Research Center, University of Turku, Turku, Finland
}

\section{A R T I C L E I N F O}

\section{Article history:}

Received 6 November 2015

Received in revised form 19 January 2016

Accepted 8 April 2016

\section{Keywords:}

Hormone replacement therapy

Finnish women

Climacteric symptoms

\begin{abstract}
A B S T R A C T
Objective: To investigate which patient characteristics are associated with the initiation of hormone replacement therapy (HRT) in a cohort of Finnish women.

Study design: Responses to postal questionnaires distributed to a nationwide, randomly selected cohort of women in 1998, 2000, 2003, 2005 and 2010 were analyzed. The cohort members were aged 40-44 years at the beginning of the study. Information on hormone replacement therapy was received from the national prescription register. Women who started taking HRT between January 1, 1999 and December 31, 2011 were included and previous users were excluded from the analysis.

Main outcome measures: Initiation of HRT was the main outcome measure. The following explanatory factors for predicting the use of HRT were examined: sociodemographic factors, personality, health behavior, physiological and mental symptoms, chronic diseases and use of psychopharmaceuticals. The associations between starting HRT and the explanatory factors were analyzed with single-predictor and multi-predictor logistic regression models.

Results: Factors predicting that a woman would start taking HRT were: living with a partner, weak sense of coherence, BMI less than $30 \mathrm{~kg} / \mathrm{m}^{2}$, heavy or moderate alcohol use, symptoms of hyperactivity of the sympathetic nervous system, climacteric symptoms and use of psychopharmaceuticals.

Conclusions: Women with a good sense of coherence can cope with climacteric symptoms without resorting to HRT. Clinicians need to bear in mind the burden of menopausal symptoms on a woman's personal and working life when HRT is being considered.
\end{abstract}

(C) 2016 Elsevier Ireland Ltd. All rights reserved.

\section{Introduction}

Estrogen-replacement therapy has been used for over 70 years [1]. The efficacy of hormone replacement therapy (HRT) in alleviating climacteric vasomotor symptoms (hot flushes and night sweats) is well documented and widely accepted. Hot flushes affect up to $70-80 \%$ of climacteric women $[2,3]$ and persist for 5 or more years past the menopause in up to a third of women [4,5]. In a Finnish study no less than $95 \%$ of women aged $52-56$ years had climacteric symptoms to some degree [6].

In Finland, women start using HRT at a median age of 50 years and use it for a median of 10 years [7]. Women who start HRT are usually more likely to be highly educated, non-obese, to drink more alcohol and experience more discomfort because of climacteric symptoms than their peers who do not use HRT [8]. A study from the UK showed that the main predictor of HRT use is the belief that its benefits outweigh its risks [9]. A major drawback of that study was, however, that only intention to use was studied, not the actual use of HRT itself.

The aim of the present study was to investigate whether various patient characteristics predict that a woman will start taking HRT among a population sample of Finnish women. In addition to sociodemographic and health risk behaviors, we also examined psychological factors such as hostility, sense of coherence, sleep disturbance and depression. Climacteric symptoms are the main indication for HRT [7], but we wanted to know to what extent personal traits are associated with the use of HRT.

\footnotetext{
* Corresponding author.

E-mail address: jaana.jalava-broman@utu.fi (J. Jalava-Broman).
} 


\section{Methods}

\subsection{Population and questionnaires}

Data were collected from the Health and Social Support (HeSSup) study. The Finnish Population Register Center established a random population sample in 1998 representative of the Finnish working-age population, stratified by age into groups aged 20-24, $30-34,40-44$ and $50-54$ years. The baseline survey was based on a comprehensive questionnaire covering psychosocial, medical and behavioral variables [10]. Fig. 1 shows sample sizes, drop-out and response rates and years of survey. The response rate to the baseline questionnaire for the HeSSup study among women aged 40-44 years in 1998 was $45.5 \%$ (3013/6616) after one reminder. In 2003, the response rate was $86.8 \%(2453 / 2826)$ after one reminder; the HeSSup questionnaire was sent only to those who had answered in 1998. In 2000, another questionnaire, as part of the 'Quality of Life Among Middle-aged Women Study' (the QoL Study), was sent to the same women aged 42-46 years who had answered the HeSSup Study two years earlier. The QoL questionnaire focused on the respondents' gynecological background, climacteric symptoms, use of HRT and other treatments for climacteric symptoms as well as matters of sexuality [6]. After one reminder 1825 women out of 2771 answered (response rate 65.9\%). Five years later in the QoL Study, in 2005, a follow-up questionnaire was sent to the same population as in 2000. At that time, 2017 women out of 2663 responded to the questionnaire after one reminder (response rate 75.7\%). Finally, in 2010 in the QoL Study, a follow-up questionnaire was sent to the same population as in 2005 and 2000. At that time 1988 women out of 2740 responded to the questionnaire after one reminder (response rate $72.6 \%$ ).

In the analysis of the HeSSup study in 1998, no specific healthrelated factors were significantly associated with non-response [10]. A similar analysis in the QoL Study in 2000 examined four factors: basic education, professional education, use of psychopharmaceuticals and employment status. Here, the responders differed from non-responders in terms of education: women with a high level of basic education and with a professional education responded more often than others [6].

The Turku University Hospital Ethics Committee considered that a statement of approval was not legally required for this questionnaire study, which dealt with a normal population cohort. The subjects in the HeSSup study originated from a random population sample drawn by the Finnish Population Register Center. When agreeing to participate in the study, the subjects signed an informed consent form that permitted subsequent studies to draw on the same data.

The primary outcome variable was the initiation of HRT. Information on the use of HRT within the study cohort was received from the prescription registers in Finland (managed by the Social Insurance Institution of Finland) and we were able to use these prescription data to determine whether a participant started HRT. The drugs were classified by the ATC-system (Anatomical Therapeutic Chemical Classification). The sales figures for HRT preparations were retrieved for estrogens (ATC G03C), progesterones (ATC G03D) and progesterones and estrogens in combination (ATC G03F). Data on the use of antidepressants (ATC N06A, ATC N06C), tranquilizers (ATC N05B) and hypnotics (ATC N05C) were collected from the same register. The data on medication were collected for the years 1994-2011. For a woman to be classified as having started HRT, the criterion was that one HRT prescription had been dispensed for her from a pharmacy. This was deemed sufficient, as we wanted to evaluate factors that might predict only whether a woman would start to use HRT (and not, say, length of use); we included all women who had bought at least one package of HRT (i.e. the purchase of the drug was equated with starting HRT - an assumption that is bolstered by the cost of the preparations).

\subsection{Explanatory factors}

The explanatory factors-participants' characteristics that might predict that she would start taking HRT after 1998-were derived from the HeSSup and the QoL questionnaires. The information from the HeSSup questionnaire of 1998 and the QoL Study of 2000 was used for women who started HRT in 1999-2003. For those who started HRT in 2004-2011, the information was collected from the identical HeSSup questionnaire of 2003 and the QoL Study of 2005. The information on women who did not start HRT at all was collected from the HeSSup Questionnaire of 2003 and QoL Study of 2005. The severity of climacteric symptoms of both HRT initiators and HRT non-initiators were assessed by the responses to the QoL questionnaires from the years 2000, 2005 and 2010.The highest severity score from these responses was used in the analysis, irrespective of the year of the questionnaire.

We evaluated the following five groups of explanatory factors: (1) sociodemographic factors, (2) personality, (3) health behavior, (4) physiological and mental symptoms and (5) chronic illnesses and use of psychopharmaceuticals.

\subsubsection{Sociodemographic factors}

The following sociodemographic variables were included in the analysis: living alone or with a partner, educational status (none/vocational/college/university or high school), working status (employed/unemployed), number of children (none/one or more) and age (year of birth).

\subsubsection{Personality and sexual satisfaction}

Two characteristics of personality were evaluated: sense of coherence (SOC) and hostility. According to Antonovsky's [11] SOC model, persons with a high SOC have the ability to benefit from their general defense mechanisms to overcome stressful situations. Assessment of a subject's SOC was based on the 13item scale of Antonovsky's Orientation to Life Questionnaire (OLQ), which formed part of the HeSSup questionnaire and were classified into three groups with lower and upper quartiles as cut-off values.

The health of hostile individuals is at greater risk than that of non-hostile individuals, due partly to a lesser ability of the former to cope with psychosocial stress [12]. Hostility was measured with three questions: 'Do you get angry easily?' (scale 1-7/easily-not easily), 'How easily do you become irritated?' (scale 1-7/very easily-not easily) and 'How often do you quarrel?' (scale 1-7/very often-very seldom or never). Hostility was measured as the sum of the scores for these three items and was dichotomized as low (values $0-12$ ) and high ( $\geq 13$ ) hostility.

Sexual satisfaction was ascertained with the question 'Are you satisfied with your sex life?', responses to which were on a scale of $1-7$, which in turn were categorized as 'very satisfied' (values 1-2), 'quite satisfied' (values 3-5) and 'not satisfied' (values 6-7). It is known that HRT significantly improves sexual function in the domains of orgasm, lubrication and pain. The level of sexual satisfaction is greater among postmenopausal women taking HRT than among those not taking it [13].

\subsubsection{Health behavior}

Physical activity was measured with the Metabolic Equivalent Task (MET) index and respondents were classified as: less than 14 MET, 14-30 MET and more than 30 MET per week [14]. Height and weight were used to calculate the body mass index (BMI) to identify underweight or normal weight (BMI $<25.0 \mathrm{~kg} / \mathrm{m}^{2}$ ), overweight (BMI 25 to $<30 \mathrm{~kg} / \mathrm{m}^{2}$ ) and obese (BMI $\geq 30 \mathrm{~kg} / \mathrm{m}^{2}$ ) subjects. Perceived health status was assessed using the question 'How is your 


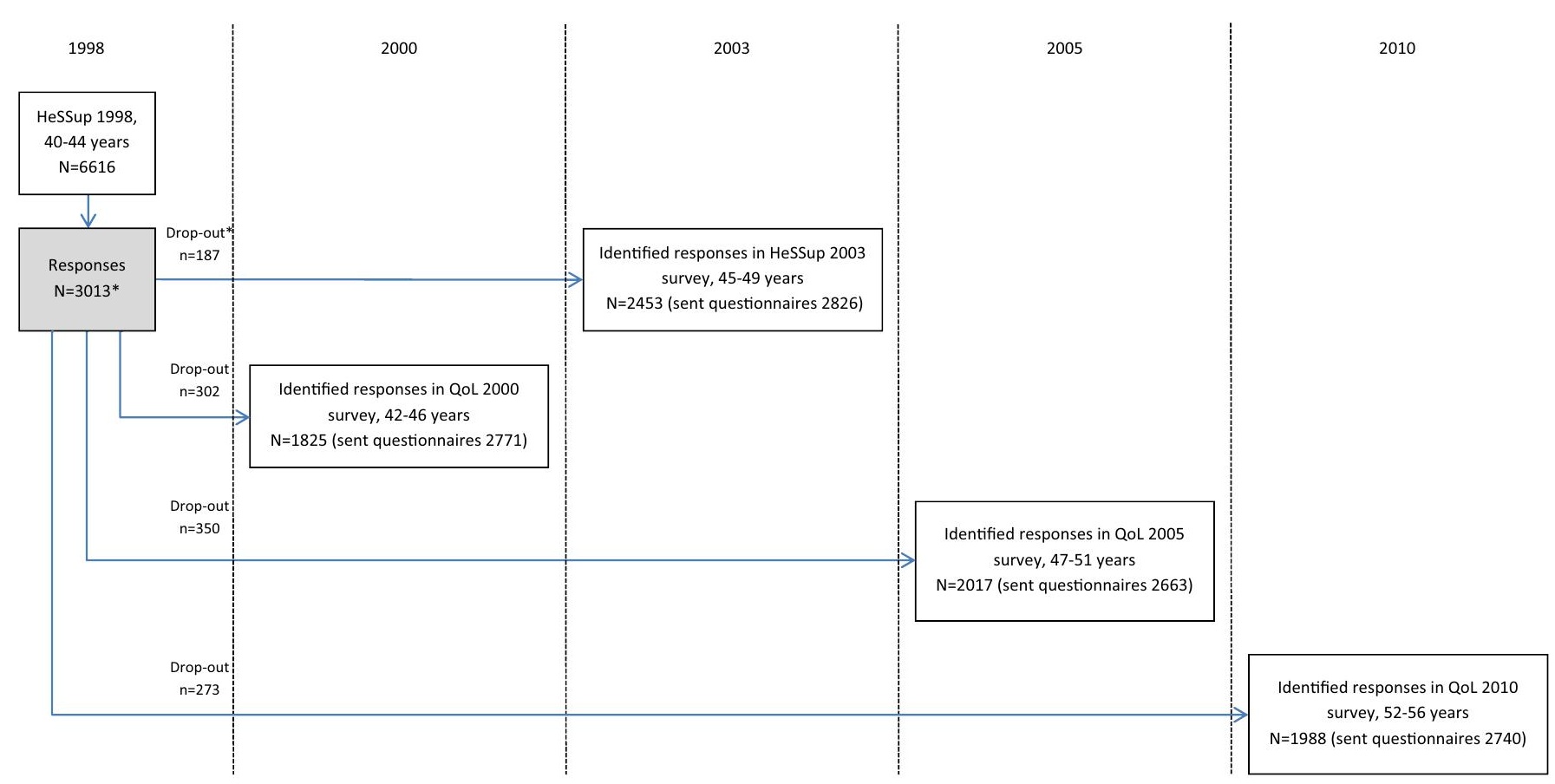

* Drop outs: due to decline to use registry data or to unclear identity.

Fig. 1. Flowchart of the women responding to the questionnaires in 1998, 2003 (HeSSup) and 2000, 2005, 2010 (QoL).

*Drop outs: due to decline to use registry data or to unclear identity.

health?' and the answer was dichotomized into two categories: good (excellent, fairly good) and poor (average, fairly poor, poor). Simple questions on self-rated health with precoded answers have proved to be strong predictors of future health problems and mortality [15]. Alcohol consumption was divided into two categories (abstinent or mild vs. moderate or heavy). The weekly reported consumption of alcohol was categorized as less than $22 \mathrm{~g}$ (abstinent/mild) or more than $22 \mathrm{~g}$ (moderate and heavy) of alcohol per week. Smoking status was classified as current, previous or never.

\subsubsection{Physiological and mental symptoms}

Symptoms of depression were measured with the Beck Depression Inventory (BDI). Depression was indicated by a BDI sum score of more than 18 [16].

Symptoms of sympathetic nervous system (SNS) hyperactivity were measured on an 8-item scale [17]. The following symptoms within the past month were asked: palpitation without exercise, irregular heartbeat, chest pain upon anger and emotion, sweating without exercise, flushing, tremor of hands, tremor of voice and muscle twitching. Four possible responses were given for each item: daily or almost daily, weekly, less often than weekly or never. According to their mean score on the 8 statements, women were classified based on tertiles as having a low, middle or high level of symptoms of SNS hyperactivity.

Sleep disturbances were measured by the subject's own estimation of her sleep quality. It was measured with a single question: 'How well do you sleep in general?', with replies on a 5-point response scale. Sleep quality was then dichotomized as undisturbed (well/rather well) or disturbed (rather poor/poor). 'Cannot say' responses were coded as missing responses [17].

The questions on climacteric symptoms were derived from earlier studies $[6,18,19]$ and covered: sweating, hot flushes, vaginal dryness and tenderness, recurrent urinary infections, urinary incontinence, sleeping problems, depression, irritability, dizziness, palpitation, dyspareunia and lack of sexual desire. A sum score was formed from the four climacteric symptoms (each rated 1-10) known to be associated with estrogen deficiency: sweating, hot flushes, vaginal dryness and tenderness, and sleeping problems. The sum score of these symptoms ranged from 2 (allowing for two missing values) to 40 . All women who had responded to at least two of the four options were accepted for statistical analysis. The symptom score was classified into four categories for the overall symptom intensity level: none, mild, moderate and severe [6].

\subsubsection{Chronic diseases, removal of ovaries and use of psychopharmaceuticals}

Chronic diseases included asthma, hypertension, psychotic depression, diabetes and diseases which contraindicate HRT use (in ICD10 codes). Chronic diseases were selected from the registers of the Social Insurance Institution of Finland. Information on psychopharmaceutical medication, which consisted of antidepressants, tranquilizers and hypnotics, was collected from the same register (by ATC-system codes). Information of removal of ovaries was acquired from the QoL questionnaire.

\subsection{Statistical analyses}

The associations between starting HRT and the different variables were analyzed with a single-predictor logistic regression model and a multi-predictor logistic regression model. The analyses were in three stages: All single-predictor associations close to statistical significance $(\mathrm{p}<0.1)$ were further analyzed in a multipredictor model with all predictors in the same block. Variables that still had a significant $(\mathrm{p}<0.1)$ association were then analyzed in the final model, where $\mathrm{p}<0.05$ was considered to indicate statistical significance. Only single and final model results are presented in this paper. The statistical calculations were made with SAS for Windows software (release 9.3, TS1MO, SAS Institute, Cary, NC, USA). 
Table 1

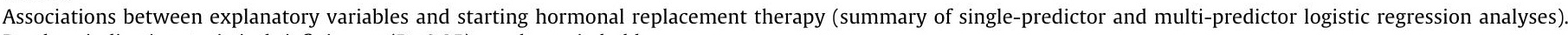
P-values indicating statistical sigfinicance $(\mathrm{P}<0.05)$ are shown in bold.

\begin{tabular}{|c|c|c|c|c|}
\hline & \multicolumn{2}{|c|}{ Single predictor models } & \multicolumn{2}{|l|}{ Final model ${ }^{\mathrm{a}}$} \\
\hline & OR $(95 \% \mathrm{CI})$ & $\mathrm{P}$ & OR $(95 \% \mathrm{CI})$ & $\mathrm{P}$ \\
\hline \multicolumn{5}{|l|}{ (Category wise $\mathrm{n}$ in parentheses) } \\
\hline \multicolumn{5}{|l|}{ Sociodemographic factors } \\
\hline Living alone & & 0.003 & & $<0.001$ \\
\hline No (334) & $1.46(1.14-1.86)$ & & $1.67(1.26-2.21)$ & \\
\hline Yes (1163) & Ref. & & Ref. & \\
\hline Educational status & & 0.160 & & \\
\hline None (159) & Ref. & & & \\
\hline Vocational (445) & $1.07(0.75-1.50)$ & & & \\
\hline College (677) & $1.31(0.93-1.85)$ & & & \\
\hline University (217) & $1.00(0.66-1.50)$ & & & \\
\hline Year of Birth & & 0.006 & & 0.119 \\
\hline $1954(303)$ & $1.44(1.04-1.99)$ & & Ref. & \\
\hline $1955(313)$ & $1.46(1.06-2.02)$ & & & \\
\hline $1956(332)$ & $1.21(0.88-1.66)$ & & & \\
\hline $1957(330)$ & $0.91(0.66-1.24)$ & & & \\
\hline $1958(289)$ & Ref. & & & \\
\hline Working & & 0.786 & & \\
\hline Unemployed (220) & Ref. & & & \\
\hline Employed (1273) & $1.04(0.78-1.39)$ & & & \\
\hline Number of children & & 0.732 & & \\
\hline None (209) & Ref. & & & \\
\hline One or more (1358) & $1.05(0.79-1.41)$ & & & \\
\hline \multicolumn{5}{|l|}{ Personality and sexual satisfaction } \\
\hline Sense of Coherence (SOC) & & $<0.001$ & & 0.012 \\
\hline Soc $0-25 \%(313)$ & $1.79(1.33-2.42)$ & & $1.62(1.13-2.32)$ & \\
\hline Soc $25-75 \%(792)$ & $1.52(1.19-1.94)$ & & $1.46(1.10-1.90)$ & \\
\hline Soc $75-100 \%(392)$ & Ref. & & Ref. & \\
\hline Hostility & & $0.044^{b}$ & & \\
\hline Low (1195) & Ref. & & & \\
\hline $\operatorname{High}(297)$ & $1.30(1.01-1.68)$ & & & \\
\hline Sexual satisfaction & & 0.843 & & \\
\hline Very satisfied (679) & Ref. & & & \\
\hline Quite satisfied (615) & $1.07(0.86-1.33)$ & & & \\
\hline Not satisfied (189) & $1.05(0.76-1.45)$ & & & \\
\hline \multicolumn{5}{|l|}{ Health behavior } \\
\hline Physical activity & & $0.062^{\mathrm{b}}$ & & \\
\hline $0 \leq \mathrm{MET}<14(381)$ & Ref. & & & \\
\hline $14 \leq \mathrm{MET}<30(494)$ & $1.31(1.00-1.71)$ & & & \\
\hline $\mathrm{MET} \geq 30(601)$ & $1.34(1.00-1.73)$ & & & \\
\hline BMI & & $<0.001$ & & $<0.001$ \\
\hline Obese (207) & Ref. & & Ref. & \\
\hline Overweight (462) & $1.73(1.24-2.42)$ & & $1.75(1.20-2.55)$ & \\
\hline Underweight/normal (820) & $2.20(1.61-3.01)$ & & $2.45(1.71-3.50)$ & \\
\hline Perceived health status & & 0.720 & & \\
\hline Good (excellent, fairly good) (1208) & Ref. & & & \\
\hline Poor (average, fairly poor, poor) (284) & $0.95(0.74-1.24)$ & & & \\
\hline Alcohol consumption & & $<0.001$ & & 0.026 \\
\hline Moderate/heavy (931) & $1.45(1.18-1.79)$ & & $1.32(1.03-1.67)$ & \\
\hline Abstinent/mild (569) & Ref. & & Ref. & \\
\hline Smoking & & 0.009 & & 0.025 \\
\hline Never (646) & Ref. & & Ref. & \\
\hline Previous (461) & $1.36(1.07-1.73)$ & & $1.25(0.96-1.60)$ & \\
\hline Current (306) & $0.90(0.68-1.17)$ & & $0.80(0.59-1.09)$ & \\
\hline Symptoms of SNS hyperactivity & & 0.005 & & $<0.001$ \\
\hline Lowest tertile (544) & Ref. & & Ref. & \\
\hline Middle tertile (565) & $1.26(0.99-1.60)$ & & $1.86(1.40-2.47)$ & \\
\hline Highest tertile (385) & $0.82(0.63-1.07)$ & & $1.34(0.98-1.84)$ & \\
\hline Depression (Beck) & & 0.434 & & \\
\hline No (1407) & Ref. & & & \\
\hline Yes (65) & $1.22(0.74-2.02)$ & & & \\
\hline Sleep quality & & 0.382 & & \\
\hline Undisturbed (well/rather well) (1230) & Ref. & & & \\
\hline Disturbed (rather poor/poor) (254) & $1.13(0.86-1.48)$ & & & \\
\hline Climacteric symptoms & & $<0.001$ & & $<0.001$ \\
\hline None $(70)$ & Ref. & & Ref. & \\
\hline Mild (655) & $1.04(0.62-1.74)$ & & $0.92(0.53-1.61)$ & \\
\hline Moderate (600) & $2.68(1.60-4.49)$ & & $2.44(1.38-4.30)$ & \\
\hline Severe (223) & $5.24(2.95-9.31)$ & & $4.68(2.48-8.83)$ & \\
\hline \multicolumn{5}{|c|}{ Chronic diseases, removal of ovaries and psychopharmaceutical medication } \\
\hline Chronic diseases & & 0.975 & & \\
\hline No (1494) & Ref. & & & \\
\hline Yes $(73)$ & $0.99(0.62-1.59)$ & & & \\
\hline Psychopharmaceuticals & & 0.006 & & 0.008 \\
\hline No (1427) & Ref. & & Ref. & \\
\hline Yes (140) & $1.66(1.16-2.37)$ & & $1.80(1.17-2.77)$ & \\
\hline Removal of ovaries & & 0.137 & & \\
\hline No (1441) & Ref. & & & \\
\hline Yes (18) & $2.1(0.79-5.66)$ & & & \\
\hline
\end{tabular}

a Final multi-predictor model; variable included if $\mathrm{p}<0.1$ in single predictor and intervening multi-predictor models.

b Predictor had too low significance level to get into the final model. 


\section{Results}

Climacteric symptoms were the main reason for a woman to start HRT. The single-predictor model showed that a larger proportion of women who started HRT had a partner than was the case among those who did not start HRT. Women who started HRT were more hostile and had a poorer sense of coherence than those who did not start HRT. A larger proportion of underweight, normal and overweight women started HRT than of obese women. Women who were physically active in their leisure time began using HRT more often than sedentary women. Larger proportions of women started HRT if they were moderate or heavy drinkers rather than abstinent or mild drinkers, and if they were former smokers rather than never smokers. A larger proportion of women with medium symptoms of SNS hyperactivity started more often HRT than was the case among those with low symptoms. A larger proportion of women who used psychopharmaceuticals started HRT than of women who did not take these drugs (Table 1 ).

The final significant predictors of starting HRT identified by the multi-predictor model were: living with a partner, BMI less than $30 \mathrm{~kg} / \mathrm{m}^{2}$, high or moderate alcohol consumption, less SOC, moderate or severe climacteric symptoms, many symptoms of sympathetic nervous system hyperactivity and use of psychopharmaceuticals (Table 1 ).

SOC and climacteric symptoms were analyzed further as predictors of HRT initiation. With climacteric symptoms as the covariate, the association between SOC and HRT initiation was still statistically significant $(p=0.002)$. These factors did not interact significantly ( 2 -way model, $\mathrm{p}=0.433$ ); that is, climacteric symptoms are not modifiers of the association between SOC and HRT initiation. Therefore, SOC seems to be associated with HRT initiation regardless of the severity of climacteric symptoms.

\section{Discussion}

This study investigated factors that predict the start of use of HRT among menopausal women. The aim was to ascertain the characteristics of an individual that lead a woman to start HRT.

We identified some of the same predictors of HRT as earlier studies. Climacteric symptoms and symptoms of sympathetic nervous system hyperactivity impair quality of life. Some women try to alleviate these symptoms by drinking alcohol or taking psychopharmaceuticals before starting HRT. Also, women with a poor SOC try to cope better with life by starting HRT.

Earlier studies have shown that vasomotor symptoms are more frequent among alcohol drinkers than non-drinkers [20,21]. In Finland, middle-aged women who consume more than 16 portions of alcohol weekly have more vasomotor symptoms than women who consume fewer than 10 portions of alcohol weekly ( 1 portion $=12 \mathrm{~g}$ pure alcohol) [22]. In our study moderate or heavy alcohol use predicted initiation of HRT.

Obesity was associated with HRT initiation, and this association was stronger in the comparison against normal-weight or underweight women than when the comparison was against overweight women. The impact of body weight and body weight changes on the occurrence of hot flushes during menopause is not clear. Below-normal or normal body weight has been reported as being determinants of HRT use [23], and the results of the present study corroborate this observation. In a recent study from Maryland, however, [24] a high BMI did not increase a woman's risk of hot flushes in midlife.

A greater proportion of women with a partner than of single women started HRT. According to earlier reports, age and declining estradiol levels have detrimental effects on sexual function. The most common sexual complaints are reduced sexual desire, vaginal dryness and dyspareunia, poor arousal and orgasm, and impaired sexual satisfaction [25]. In these situations, HRT can improve sex life. Women in their fifties usually have marked climacteric symptoms and most of them are still professionally active in Finland. In our study women of this age started HRT, but there was no association between working status and HRT initiation. Earlier studies have shown that menopausal transition with climacteric symptoms causes difficulties for some women at work, such as poor concentration, tiredness, poor memory, feeling low/depressed and low self-esteem. In these situations, HRT can help women to cope better at work [26].

This study shows that a poor sense of coherence and symptoms of SNS hyperactivity affect the decision to start HRT. These factors have not previously been reported as being related to initiation of HRT. The finding is, nevertheless, quite feasible, since people with a high sense of coherence have a better ability to control stress [11]. Maybe women who have better stress control have a higher threshold for starting HRT than those who find stress control demanding. Also, autonomic sympathetic symptoms are quite similar to climacteric symptoms and impair the quality of everyday life.

It was surprising that sleeping problems were not associated with starting HRT in the present study, as previous studies have shown that estrogen alleviates sleeping problems, especially when sleep is impaired by night sweats [27]. A recent study from Finland showed that even a low frequency of night sweats disturbs sleep during the menopause, while only a high frequency of night sweats disturbs the sleep of premenopausal women [28]. Maybe the inclusion of CNS symptoms and of climacteric symptoms in the same model partly accounts for the association between sleeping problems and starting HRT. Previous studies indicate, however, that neither middle-aged premenopausal women nor older postmenopausal women benefit from HRT in terms of sleep quality [29].

Women with depression did not start HRT more than their nondepressed counterparts. However, a larger proportion of women using psychopharmaceuticals than of non-users did start HRT. In short-term randomized, placebo-controlled studies, estradiol has demonstrated efficacy for the treatment of depressive symptoms in perimenopausal women [30].

The strength of the present study is that it draws on a large, population-based sample and a set of comprehensive questionnaires with well-validated questions assessing social background, personal resources, personality, health behaviors and medical matters (medications, depressive symptoms, chronic diseases). The study was longitudinal and accurately describes Finnish menopausal woman. The total response rate (men and women) in 1998 in the HeSSup questionnaire was $47.0 \%$. We used in our study one cohort of women from the HeSSup study (40-44 years old, response rate $45.5 \%$ ).

A limitation of the present study is the rather low baseline questionnaire response rate of the HeSSup-survey, although it has been shown that the data are representative of the target population [10]. At follow-up in 2003, the response rate in the HeSSup-survey was high, over $80 \%$ of those who had answered in 1998 [31]. In our QoL-study the response rate was fair or good in 2000 (66\%), 2005 (76\%) and in 2010 (65.9\%).

\section{Conclusions}

Moderate or severe climacteric symptoms are strong predictors of imminent HRT use. Women with a good sense of coherence (which usually means good stress tolerance and an ability to cope with stress) seem more able to manage without HRT. On the other hand, women with sleeping problems or depression start using 
HRT to a similar extent as women with no sleeping problems or depression. Climacteric symptoms need to be discussed in depth during clinical appointments. In these situations, women with a low sense of coherence, i.e., a poor ability to tolerate stress, may be appropriately referred for consideration of HRT.

\section{Contributors}

P.R., J.M., J.V., L.S. and J.J.-B. were involved in the conception and design of the research. P.R., J.M., J.J.-B. and L.S. were involved in collecting data. L.S. performed statistical analysis. P.R., J.M., J.V., L.S. and J.J.-B. performed drafting of the manuscript. All the authors were involved in critically revising the manuscript for its intellectual content and approving the final version.

\section{Funding}

No funding was received for this article.

\section{Ethical approval}

The study was performed according to the principles established with the revised declaration of Helsinki, and approved by the Ethics Committee of the Hospital District of Southwest Finland.

\section{Provenance and peer review}

This article has undergone peer review.

\section{Conflict of interest}

None.

\section{References}

[1] M. Stefanik, Estrogens and progestins: background and history, trends in use, and guidelines and regimens approved by the US Food and Drug Administration, Am. J. Med. 118 (2005) 64S-73S.

[2] V. Stearns, L. Ullmer, J.F. Lopez, Y. Smith, C. Isaacs, D. Hayes, Hot flushes, Lancet 360 (2002) 1851-1861.

[3] H. Nelson, Menopause, Lancet 371 (2008) 760-770.

[4] A. Huang, D. Grady, V. Jacoby, T. Blackwell, D. Bauer, G. Sawaya, Persistent hot flushes in older postmenopausal women, Arch. Int. Med. 168 (2008) 840-846.

[5] V.M. Barnabei, D. Grady, D.W. Stovall, J.A. Cauley, F. Lin, C.A. Stuenkel, et al., Menopausal symptoms in older women and the effects of treatment with hormone therapy, Obstet. Gynecol. 100 (2002) 1209-1218.

[6] K. Jokinen, P. Rautava, J. Mäkinen, A. Ojanlatva, J. Sundell, H. Helenius, Experience of climacteric symptoms among 42-46 and 52-56-year-old women, Maturitas 46 (2003) 199-205.

[7] J. Jalava-Broman, J. Mäkinen, A. Ojanlatva, K. Jokinen, L. Sillanmäki, P. Rautava, Chance in the frequency of HRT use from 2000 to 2005 and reasons to discontinue; follow-up of a normal cohort in Finland, Acta. Obstet. Gynecol. Scand. 90 (2011) 351-357.

[8] J. Jalava-Broman, J. Mäkinen, A. Ojanlatva, K. Jokinen, L. Sillanmäki, P. Rautava, Treatment of climacteric symptoms in Finland prior to the controversial reports on hormone therapy, Acta. Obstet. Gynecol. Scand. 87 (2008) 682-686.
[9] E. Simpson, Predictors of intentions to use hormone replacement therapy in clinical postmenopausal women, Climacteric 15 (2012) 173-180.

[10] K. Korkeila, S. Suominen, J. Ahvenainen, A. Ojanlatva, P. Rautava, H. Helenius, et al., Non-response and related factors in nationwide health survey, Eur. J. Epidemiol. 17 (2001) 991-999.

[11] A. Antonovsky, The structure and properties of the sense of coherence scale, Soc. Sci. Med. 25 (1993) 725-733.

[12] M. Kivimäki, J. Vahtera, M. Koskenvuo, A. Uutela, J. Pentti, Response of hostile individuals to stressful change in their working lives: test of a psychosocial vulnerability model, Psychol. Med. 28 (1998) 903-913.

[13] M. González, G. Viáfara, F. Caba, E. Molina, Sexual function, menopause and hormone replacement therapy (HRT), Maturitas 48 (2004) 411-420.

[14] B.E. Ainsworth, W.L. Haskell, A.S. Leon, D.R. Jacobs, H.J. Montoye, J.F. Sallis, et al., Compendium of physical activities: classification of energy costs of human physical activities, Med. Sci. Sports Exercise 25 (1993) 71-80.

[15] S. Heistaro, P. Jousilahti, E. Lahelma, E. Vartiainen, P. Puska, Self rated health and mortality: a long term prospective study in eastern Finland, J. Epidemiol. Commun. Health 55 (2001) 227-232.

[16] A.T. Beck, R.A. Steer, M.G. Garbin, Psychometric properties of the Beck Depression Inventory; twenty-five years evaluation, Clin. Psychol. Rev. 8 (1988) 77-100.

[17] J. Vahtera, M. Kivimäki, C. Hublin, K. Korkeila, S. Suominen, T. Paunio, et al., Liability to anxiety and severe life events as predictors of new-onset sleep disturbances, Sleep 30 (2007) 1537-1546.

[18] E. Stadberg, L.-A. Mattsson, I. Milsom, Factors associated with climacteric symptoms and the use of hormone replacement therapy, Acta Obstet. Gynecol. Scand. 79 (2000) 282-292.

[19] H.S. Kupperman, M.H. Blatt, H. Wiesbader, W. Filler, Comparative clinical evaluation of estrogenic preparations by the menopausal and amenorrheal indices, Endocrinology 13 (1953) 688-703.

[20] F. Parazzini, P. Di Donato, N.A. Giulini, A. Bacchi Modena, G. Cicchetti, G. Comitini, et al., Factors associated with climacteric symptoms in women around menopause attending menopause clinics in Italy, Maturitas 52 (2005) $181-189$.

[21] R. Katainen, T. Siirtola, J. Engbom, R. Erkkola, P. Polo-Kantola, A population-based survey of quality of life in middle-aged Finnish women, Menopause 22 (2014) 402-413.

[22] J. Moilanen, A.-M. Aalto, E. Hemminki, A.R. Aro, J. Raitanen, R. Luoto, Prevalence of menopause symptoms and their association with lifestyle among Finnish middle-aged women, Maturitas 67 (2010) 368-374.

[23] Y. Du, H.-U. Melchert, M. Schäfer-Korting, Hormone replacement therapy in Germany: determinants and possible health-related outcomes results of national health surveys from 1984 to 1999, Maturitas 52 (2005) 223-234

[24] L. Gallicchio, S.R. Miller, J. Kiefer, T. Greene, H.A. Zacur, J.A. Flaws, Change in body mass index, weight, and hot flushes: a longitudinal analysis from the midlife women's health study, J. Womens Health 23 (2014) 231-237.

[25] R.E. Nappi, M. Lachowsky, Menopause and sexuality: prevalence of symptoms and impact on quality of life, Maturitas 63 (2009) 138-141.

[26] A. Griffiths, S. MacLennan, J. Hassard, Menopause and work. An electronic survey of employeesí attitudes in the UK, Maturitas 76 (2013) 155-159.

[27] P. Polo-Kantola, Estrogeeni ja uni [Estrogen and sleep], Duodecim 116 (2000) 1689-1695.

[28] L. Lampio, P. Polo-Kantola, O. Polo, T. Kauko, J. Aittokallio, T. Saaresranta, Sleep in midlife women: effects of menopause, vasomotor symptoms, and depressive symptoms, Menopause 21 (2014) 1217-1224.

[29] N. Kalleinen, O. Polo, S.-L. Himanen, A. Joutsen, P. Polo-Kantola, The effect of estrogen plus progestin treatment on sleep: a randomized, placebo-controlled, double-blind trial in premenopausal and late postmenopausal women, Climacteric 11 (2008) 233-243.

[30] P.J. Schmidt, L. Nieman, M.A. Danaceau, M.B. Tobin, C.A. Roca, J.H. Murphy, et al., Estrogen replacement in perimenopausal-related depression: a preliminary report, Am. J. Obstet. Gynecol. 183 (2000) 414-420.

[31] M. Sumanen, A. Rantala, L.H. Sillanmäki, K.J. Mattila, Childhood adversities experienced by working-age migraine patients, J. Psychosom. Res. 62 (2007) $139-143$. 